\title{
Analyst
}

Check for updates

Cite this: Analyst, 2020, 145, 7303

\section{Siderophore purification with titanium dioxide nanoparticle solid phase extraction $\uparrow$}

\author{
Philipp H. Egbers, ${ }^{a}$ Tilmann Harder, (DD ${ }^{a, b}$ Boris P. Koch (D) ${ }^{b, c}$ and Jan Tebben (D) $* b$
}

Siderophores are metal chelators produced by microorganisms to facilitate binding and uptake of iron. The isolation and characterization of siderophores are impeded by typically low siderophore yields and the complexity of siderophore-containing extracts generated with traditional purification methods. We investigated titanium dioxide nanoparticle solid-phase extraction $\left(\mathrm{TiO}_{2} \mathrm{NP}\right.$ SPE) as a technique to selectively concentrate and purify siderophores from complex matrices for subsequent LC-MS detection and identification. $\mathrm{TiO}_{2}$ NP SPE showed a high binding capacity $\left(15.7 \pm 0.2 \mu \mathrm{mol} \mathrm{mg} \mathrm{mg}^{-1} \mathrm{TiO}_{2}\right)$ for the model siderophore desferrioxamine $\mathrm{B}$ (DFOB) and proved robust to $\mathrm{pH}$ changes and the presence of EDTA. These are significant advances in comparison to immobilized metal affinity chromatography (IMAC). The $\mathrm{TiO}_{2}$ NP SPE was highly selective and recovered $77.6 \pm 6.2 \%$ of DFOB spiked to a compositionally complex bacterial culture supernatant. The simple clean-up procedure removed the majority of contaminants and allowed direct detection of siderophores from the LC-MS base peak chromatogram. The 'untargeted' purification and analysis of an untreated supernatant of iron-deprived bacterial culture allowed for the direct identification of two known and three novel ferrioxamines. Thus, $\mathrm{TiO}_{2} \mathrm{NP}$ SPE in combination with LC-MS offers great potential as a discovery platform for the purification and subsequent quantification or identification of novel siderophores of microbial origin.

Received 11th May 2020

Accepted 16th August 2020

DOI: $10.1039 / \mathrm{d} 0 \mathrm{an} 00949 \mathrm{k}$

rsc.li/analyst egies have been employed to separate and concentrate siderophores prior to analysis such as reversed-phase, size-exclusion and ion exchange chromatography and solid-phase extraction (SPE).$^{5-7}$ These techniques often have poor chromatographic recoveries for siderophores and are non-selective, resulting in concentrated yet complex samples. Recent advances in liquid chromatography-mass spectrometry (LC-MS) have facilitated the identification of siderophores in these complex extracts. ${ }^{8-12}$ However, these techniques produce many false positives, due to complex mass signatures or have reduced intensities and detection thresholds due to ion suppression by co-eluting substances. Further, these analyses also have an analytical bias against molecules that do not retain the metal ion after ionization.

To overcome these disadvantages and reduce the complexity of siderophore extracts, chromatographic techniques can target the selective binding of functional groups common to siderophores, namely catecholates, hydroxamates, and $\alpha$-hydroxycarboxylates. ${ }^{2}$ Immobilized metal affinity chromatography (IMAC), for example, relies on the inherent metal affinity of siderophores to bind to the free coordination sites of immobilized metal complexes and is routinely utilized for the selective extraction of siderophores from liquid media. ${ }^{13,14}$ IMAC, however, has a few limitations that reduce its range of methodological applications. For example, IMAC shows the best siderophore (hydroxamate) adsorption for samples 
around $\mathrm{pH} 9^{13,14}$ which requires that the spent medium or sample is adjusted to $\mathrm{pH} 9$ prior to adsorption. It would be advantageous to develop a $\mathrm{pH}$ independent chromatographic method to both ensure minimal processing and limit changes to the natural ratio of complexed $v s$. free ligands in the sample. Furthermore, some ligands have higher complex stability constants for the immobilized cations (e.g. Fe or Ni) than the IMAC resin itself and may remove these cations from the IMAC resin. This can either lead to the elution of the complexed ligand or decrease the number of available binding sites. ${ }^{13,15}$ As IMAC only binds free ligands, ${ }^{13,14,16}$ consequently, samples with a high proportion of complexed ligands require a decomplexation step. Decomplexation can be achieved with agents such as EDTA, however, these ligands then need to be chromatographically removed from the sample because they may strip metal cations from IMAC and thereby reduce available binding sites. ${ }^{13}$

In this study, we investigated metal oxide chromatography, specifically titanium dioxide $\left(\mathrm{TiO}_{2}\right)$ nanoparticle $\mathrm{SPE}$, as a technique to selectively concentrate and purify metal ligands. $\mathrm{TiO}_{2}$ is routinely used in catalysis and for the production of ceramics, paints and solar cells ${ }^{17}$ and for the adsorption of molecules such as phosphopeptides and phospholipids with functional groups of high electron density. ${ }^{18,19}$ Dziomba et al. showed that this adsorption capacity could also be used for extraction of smaller hydrophilic phosphocompounds, like thiamine phosphates. $^{20}$ Catecholates, hydroxamates and mixed ligands also adsorb on $\mathrm{TiO}_{2}$ surfaces, ${ }^{21-23}$ suggesting that $\mathrm{TiO}_{2}$ may be suitable as solid phase for siderophores. Elution of these compound classes from $\mathrm{TiO}_{2}$, however, was not reported. In general, $\mathrm{TiO}_{2}$ binds anions at low $\mathrm{pH}$ and cations at high $\mathrm{pH}$ due to the unsaturated Lewis acid site on the $\mathrm{TiO}_{2}$ surface. ${ }^{24}$ The strength and bond type between target compound and $\mathrm{TiO}_{2}$ depends on the respective functional group and corresponding affinity of the analyte, $\mathrm{TiO}_{2}$ crystalstructure, $\mathrm{pH}$ and ionic strength of the surrounding medium. ${ }^{25-27}$

We developed a reliable and selective SPE method for the chromatographic purification of siderophores from aqueous media. We then tested this method by spiking and extracting a siderophore standard from a highly complex bacterial culture supernatants because these are the main target for the discovery of novel siderophores and pose analytic challenges due to a plethora of compounds that interfere with chromatographic purification and detection. ${ }^{8}$ Our method successfully reduced the amount of interfering compounds and enabled the untargeted analysis and identification of both complexed and free ligands by LC-MS.

\section{Experimental}

\section{Chemicals and stock solutions}

All glassware and vessels were acid washed unless noted otherwise. Chemicals used for the preparation of the saline aqueous matrix and bacterial growth medium (see ESI $\dagger$ ) were all reagent grade (Roth, Sigma-Aldrich or VWR). Both media were treated with Chelex 100 (Bio-Rad, USA) prior to use. The Chelex resin was regenerated as described by the manufactures protocol. Methanol (MeOH) and formic acid (FA) were HPLC grade (Roth, VWR). $\mathrm{TiO}_{2}$ nanopowder with $21 \mathrm{~nm}$ primary particle size (Sigma-Aldrich) and Chromabond $\mathrm{C}_{18}$ Hydra $1 \mathrm{~mL}$ per $100 \mathrm{mg}$ SPE cartridges (Macherey-Nagel) were used as sorbent materials. $\mathrm{NaH}_{2} \mathrm{PO}_{4}, \mathrm{NaOH}$ and $\mathrm{NH}_{3}$ (all VWR) were used for the eluents. Desferrioxamine B (DFOB) was prepared from desferrioxamine mesylate (Sigma-Aldrich) dissolved to the final concentration of $74.4 \pm 0.8 \mu \mathrm{M}$ in iron free saline aqueous matrix and $86.5 \mu \mathrm{M}$ bacterial supernatants, respectively. The high concentrations of DFOB (in comparison to realistic environmental concentrations) were used to reduce the complexation of DFOB with background contaminants ( $\mathrm{Fe}, \mathrm{Al}$, Ti) in order to accurately calculate binding capacities as well as recoveries and to compare the data to similar concentrations used in the literature. ${ }^{13,14}$ The Fe complex ferrioxamine $\mathrm{B}$ (FOB) was prepared saturating $95 \mathrm{~mL}$ of a $114 \mu \mathrm{M}$ DFOB solution with $5 \mathrm{~mL}$ of $44 \mathrm{mM} \mathrm{FeCl} 3\left(\mathrm{FeCl}_{3} \cdot 6 \mathrm{H}_{2} \mathrm{O}\right.$, Sigma-Aldrich) in ultrapure water. Seven eluents were tested: $\mathrm{MeOH} 100 \%$ (E1), $\mathrm{FeCl}_{3} 200 \mu \mathrm{M}, \mathrm{pH} 3.3$ (E2), $\mathrm{NH}_{3}$ 10\%, pH 12.6 (E3), $\mathrm{NaH}_{2} \mathrm{PO}_{4} 2.5 \mathrm{M}, \mathrm{pH} 8$ (E4), $\mathrm{NaH}_{2} \mathrm{PO}_{4} 100 \mathrm{mM}, \mathrm{pH} 8$ (E5), $\mathrm{NaH}_{2} \mathrm{PO}_{4} 100 \mathrm{mM}$, pH 11 (E6) and $\mathrm{NaH}_{2} \mathrm{PO}_{4} 100 \mathrm{mM}$, pH 12.6 (E7). For the FOB calibration, dilution series were prepared in triplicate in ultrapure water (Fig. S4 $\dagger$ ).

\section{Instrumental}

For extraction experiments, a vortex mixer (Genius 3, IKA) and centrifuge (Eppendorf) were used. A cryomill (Retsch) was used without grinding balls to shake screw cap micro tubes (Sarstedt) in order to re-suspend $\mathrm{TiO}_{2}$ pellets in the eluents. LC-HRMS analysis was performed with a Vanquish UPLC system coupled to a Q-Exactive Plus mass spectrometer, using a heated electrospray ionization source (both Thermo Fisher Scientific). Separation was performed on a $\mathrm{C}_{18}$ column (C18 $\mathrm{BEH}, 100 \times 2 \mathrm{~mm}, 1.7 \mu \mathrm{m}$ particle size, ACQUITY Waters, equipped with guard-column). Positive Ion Calibration Solution (Pierce, Thermo Fisher Scientific) was used for the calibration of the instrument. $1.5 \mathrm{~mL}$ short threat brown glass vials (Thermo Fisher Scientific) were used for all LC-HRMS measurements. Following solvent compositions and gradient settings were used: Solvent $\mathrm{A}=0.1 \%$ formic acid in ultrapure water, solvent $\mathrm{B}=0.1 \%$ formic acid in methanol; $T_{0} \min : \mathrm{B}=$ $1 \%, T_{0.2} \min \mathrm{B}=1 \%, T_{4 \min }: \mathrm{B}=100 \%, T_{4.9} \min : \mathrm{B}=100 \%$; $T_{5}$ min: $\mathrm{B}=1 \%$ with a flow rate of $0.4 \mathrm{~mL} \mathrm{~min}^{-1}$. The first $1.4 \mathrm{~min}$ of the LC method were kept at isocratic conditions and the flow diverted to avoid spaying nonvolatile salts into the mass spectrometer. MS measurements were performed using electrospray ionization in positive mode. Full MS mode with a resolution of $70000\left(\mathrm{~m} / \mathrm{z}^{2} 200\right)$ and a scan range of 300 to $1500 \mathrm{~m} / \mathrm{z}$ was used for analyte quantification.

Data dependent (Top 5) mode was used for the untargeted screening with a full scan at $70000(\mathrm{~m} / \mathrm{z} 200)$ followed by five $\mathrm{MS}^{2}$ experiments (Top $N$ ) at normalized collision energy (NCE) of 30 , AGC target of $3 \times 10^{6}$ and $50 \mathrm{~ms}$ maximum injection 
time. For siderophore identification, an inclusion mass list was compiled and used for $\mathrm{MS}^{2}$ experiments in data independent (DIA) mode with a resolution of $280000(\mathrm{~m} / \mathrm{z} 200)$ and stepwise NCE 20, 30 and 40. The spray voltage for all experiments was $3 \mathrm{kV}$. Capillary temperature was set to $320^{\circ} \mathrm{C}$ and the sheath gas was set to 5. Calibration was done using the Calmix standard (Thermo Fisher Scientific).

\section{Standardized siderophore adsorption}

$1 \mathrm{~mL}$ DFOB $(74.4 \pm 0.8 \mu \mathrm{M}$ in saline aqueous matrix) were extracted with $100 \mu \mathrm{L} \mathrm{TiO}_{2} \mathrm{NP}$ suspension (2, 4, 6, 8 and $10 \mathrm{~g}$ $\mathrm{L}^{-1}$, each $n=3$ ) in $2 \mathrm{~mL}$ screw cap micro tubes (Sarstedt) by vortexing for $20 \mathrm{~min}$ (Fig. 1). After centrifugation $(14000 \mathrm{rpm}$, $2 \mathrm{~min}$ ), supernatants were collected by decantation and the $\mathrm{TiO}_{2}$-NP was re-suspended by shaking ( $3 \mathrm{~min}$ at $30 \mathrm{~Hz}$ ) in $1 \mathrm{~mL}$ ultrapure water followed by 5 min vortexing. This process was repeated twice. Desorption of DFOB was performed with $2 \times$ $1 \mathrm{~mL}$ eluent (seven different eluents used, see chemicals and stock solutions) using the same procedure. Each eluent $(1 \mathrm{~mL})$ was neutralized to $\mathrm{pH}$ 7-8 immediately with formic acid in ultrapure water to limit potential analyte hydrolysis after elution ( $3 \mathrm{~min}$ shaking at $30 \mathrm{~Hz}$, vortexing $10 \mathrm{~min}$ ) and centrifugation $(14000 \mathrm{rpm}, 2 \mathrm{~min})$. After $\mathrm{pH}$ adjustment, all $1.5 \mathrm{~mL}$ micro tubes were centrifuged again $(14000 \mathrm{rpm}$, $20 \mathrm{~min}$ ) to achieve particle free samples for analysis. A $10 \mu \mathrm{L}$ aliquot was taken from each sample, filled into untreated LCvials (La-Pha-Pack/Thermo Fisher Scientific), diluted 100-fold with ultrapure water and spiked with $\mathrm{FeCl}_{3}(5 \mu \mathrm{M}$ final concentration). Samples were stored at room temperature for $48 \mathrm{~h}$ before analysis to achieve complete complexation of iron by DFOB. The experiment was repeated three times to obtain independent replicates. Preliminary tests revealed that the DFOB complexes of $\mathrm{Fe}(\mathrm{III})-\mathrm{FOB}$ and $\mathrm{Al}(\mathrm{III})-\mathrm{AlOB}^{28}$ occurred concurrently. A calibration experiment with FOB and AlOB prepared from $\mathrm{DFOB}$ with addition of $\mathrm{Fe}(\mathrm{III})$ or $\mathrm{Al}(\mathrm{III})$ in excess found equivalent peak areas for both species (Fig. S2 $\dagger$ ). Therefore, we used both AlOB and FOB individually as well as the sum of both peaks for the quantification with similar results. This quantification was not affected by differences in the salinity of the sample matrix (Fig. S3†).

\section{DFOB-spiked complex siderophore samples}

A Pseudoalteromonas sp. bacterium (originally isolated from surface seawater at $69^{\circ} 25.662^{\prime} \mathrm{N} 019^{\circ} 01.458^{\prime} \mathrm{E}$ on expedition HE533) was cultured in iron free saline growth medium (see $\mathrm{ESI} \dagger$ ) for $7 \mathrm{~d}$ at $18{ }^{\circ} \mathrm{C}$ with orbital shaking at $120 \mathrm{rpm}$ in an acid washed glass flask. The cell free supernatant of was collected by centrifugation (14000 rpm, $2 \mathrm{~min}$ ). The cell free supernatant tested positive for siderophore production in the chrome-azurol assay (CAS) and Atkin's hydroxamate assay. ${ }^{29,30}$ The supernatant was analyzed by LC-HRMS and showed no presence of DFOB or corresponding metal complexes. Therefore, this supernatant was suitable for (i) spiking experiments with DFOB to study siderophore recovery from a highly complex matrix and (ii) to test 'untargeted' extraction of other siderophores causative for the positive result of the CAS and Atkins assays. $\mathrm{TiO}_{2} \mathrm{NP}$ were used to directly adsorb siderophores from a complex sample matrix. For this, $1 \mathrm{~mL}$ of the CAS and Atkin's assay positive bacterial culture supernatant was spiked with DFOB (86.5 $\mu \mathrm{M}$ final concentration) and extracted as above, using $100 \mathrm{mg}$ of $\mathrm{TiO}_{2}$, adding a washing step with $1 \mathrm{~mL} 0.02 \% \mathrm{FA} / \mathrm{MeOH}$ ( $\mathrm{pH} 2.5$ ) to separate hydroxamate-containing siderophores from other non-specifically bound molecules before desorption with E7 (Fig. 2, for protocol see ESI $\dagger$ ). The same spiked culture supernatant was extracted with a $\mathrm{C}_{18}$-SPE cartridge for comparison. Before extraction, the $\mathrm{C}_{18}$-SPE cartridge was conditioned with $2 \mathrm{~mL}$ $\mathrm{MeOH}$ and then with $4 \mathrm{~mL}$ ultrapure water. $1 \mathrm{~mL}$ of the supernatant was passed through the equilibrated $\mathrm{C}_{18}$-SPE cartridge with a flow rate not exceeding one drop per second. The $\mathrm{C}_{18^{-}}$
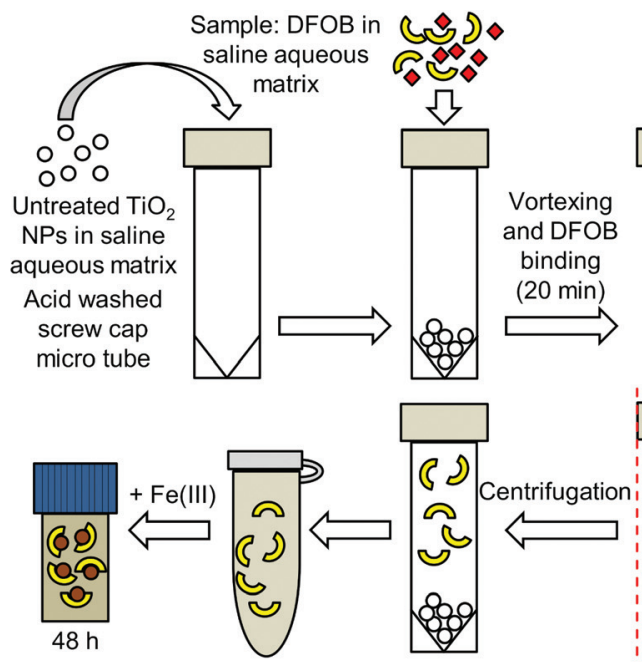

UPLC-HRMS Supernatant adjusted to neutral $\mathrm{pH}$

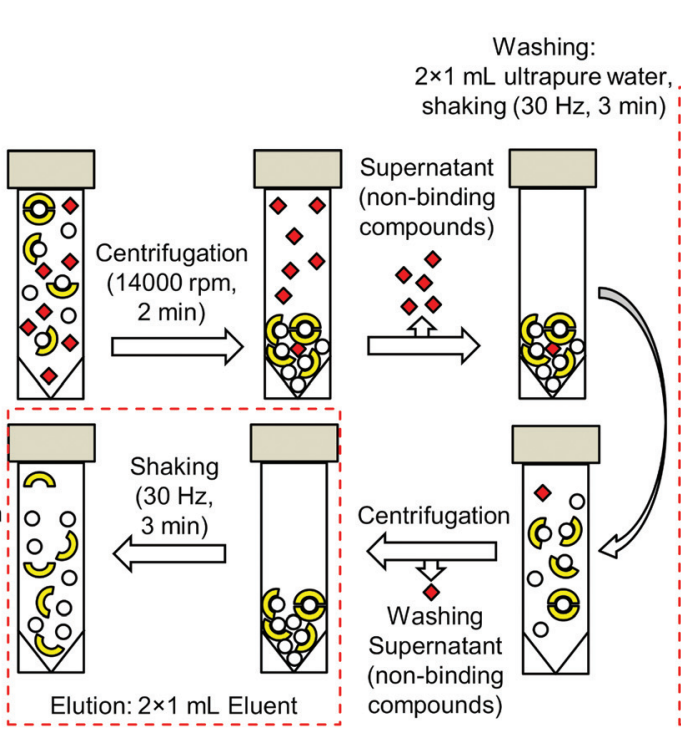

Fig. 1 Scheme for the $\mathrm{TiO}_{2}$ NP phase extraction of hydroxamates from saline aqueous matrices. 


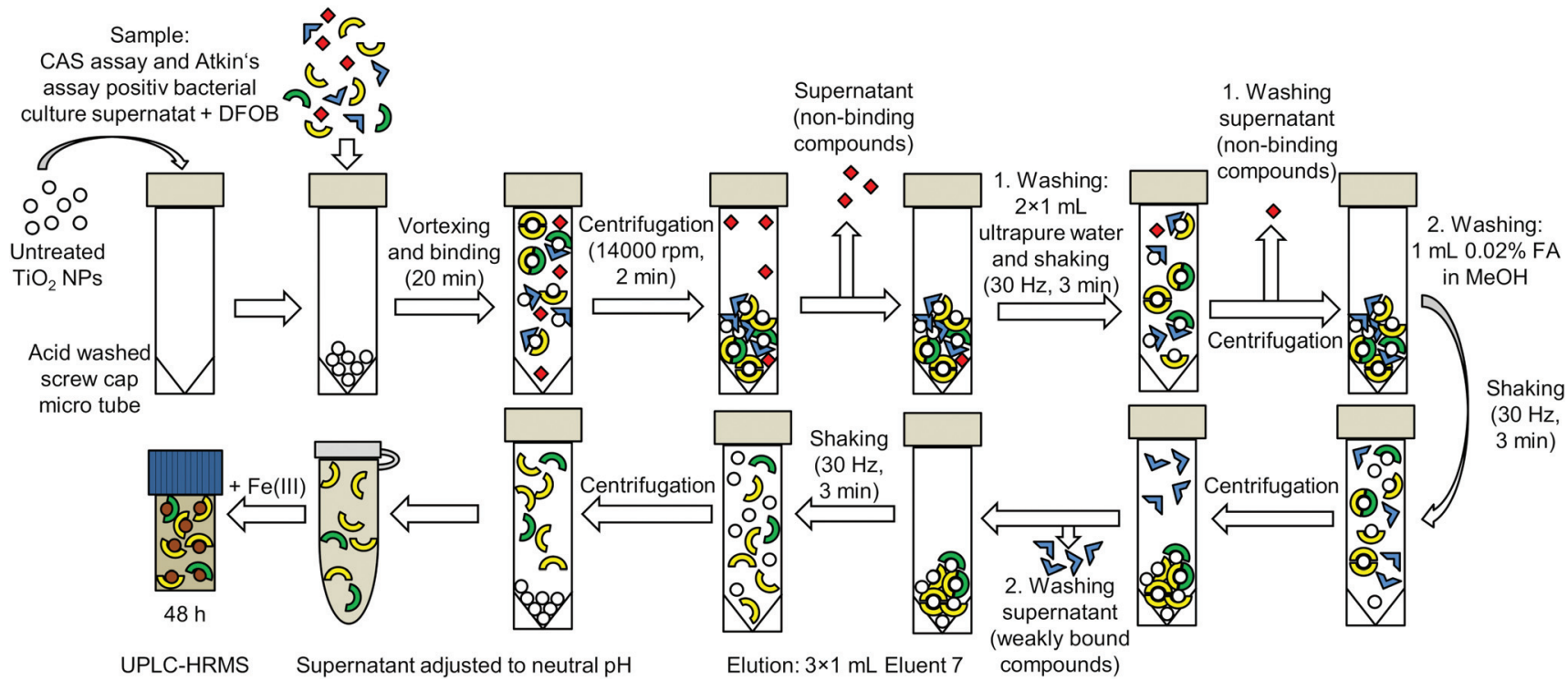

Fig. 2 Scheme for the $\mathrm{TiO}_{2}$ NP phase extraction of hydroxamate containing siderophores from crude bacterial culture supernatants.

SPE cartridge was desalted with $4 \mathrm{~mL}$ ultrapure water, dried under vacuum and eluted with $1 \mathrm{~mL} \mathrm{MeOH}$. Samples from both SPE techniques were collected in untreated LC-vials and spiked with $\mathrm{FeCl}_{3}(10 \mu \mathrm{M}$ final concentration). The experiment was repeated three times to obtain independent replicates.

\section{Decomplexation of metal complexes}

FOB stock solution was prepared by adding $50 \mu \mathrm{L} \mathrm{FeCl}_{3}$ $(2 \mathrm{mM})$ to $4.95 \mathrm{~mL}$ of aqueous DFOB solution $(60.6 \mu \mathrm{M})$. The prepared FOB stock solution was diluted 5 fold with aqueous EDTA solution (300 mM, pH 8) to a final volume of $1 \mathrm{~mL}$, stored at room temperature for $24 \mathrm{~h}$ to achieve decomplexation of FOB and then extracted with $10 \mathrm{mg}$ of $\mathrm{TiO}_{2}$ as described above (Fig. 2). A control of the FOB stock solution was diluted with ultrapure water instead of EDTA and otherwise treated identically.

\section{Results and discussion}

\section{$\mathrm{TiO}_{2}$ NP binding capacity for the model siderophore DFOB}

The binding of DFOB from $1 \mathrm{~mL}$ saline aqueous matrix onto $\mathrm{TiO}_{2}$ NPs was tested with a fixed concentration of the standard $(74.4 \pm 0.8 \mu \mathrm{M})$ and variable amounts of sorbent $(2-50 \mathrm{mg})$. We observed a linear increase of binding up to $8 \mathrm{mg} \mathrm{\textrm {TiO } _ { 2 } \mathrm { NPs }}$ and close to $100 \%$ from 10 to $50 \mathrm{mg} \mathrm{TiO}_{2}$ NPs (Fig. 3). This corresponded to a binding capacity of $15.7 \pm 0.2 \mu \mathrm{mol}$ DFOB per $\mathrm{mg}$ of $\mathrm{TiO}_{2} \mathrm{NPs}$ calculated for the linear range between 2 and $8 \mathrm{mg}$ according to Krenkova et al. ${ }^{31}$ This revealed an approximately 1000 times higher binding capacity of $\mathrm{TiO}_{2}$ for DFOB than for the phosphocompounds TMP or TPP (Table S8 $\dagger$ ). The alternative calculation method of Gu et al. ${ }^{14}$ resulted in a binding capacity of $8.8 \pm 0.1 \mu \mathrm{mol} \mathrm{mg}^{-1}$.

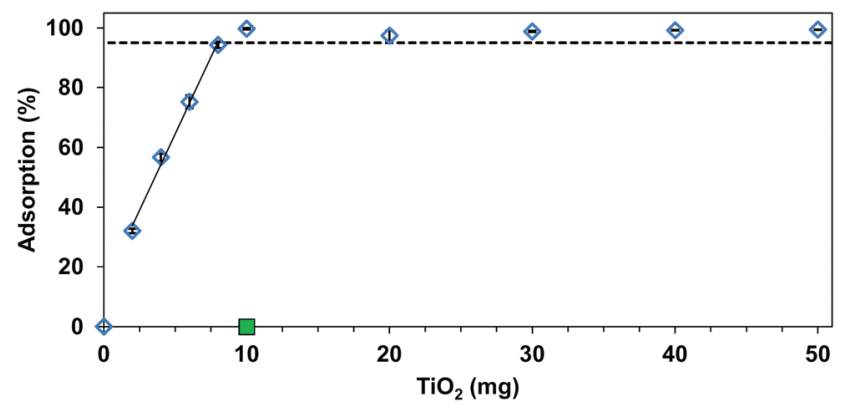

Fig. 3 Adsorption efficiency of DFOB $(74.4 \pm 0.8 \mu \mathrm{M})$ from $1 \mathrm{~mL}$ aqueous saline matrix depending on $\mathrm{TiO}_{2} \mathrm{NP}$ amount (blue diamonds). Error bars are standard deviation $(n=3)$. The linear range $(2-8 \mathrm{mg})$ was used for binding capacity calculation according to Krenkova et al. (black solid line). ${ }^{31}$ The binding capacity according to Gu et al. ${ }^{14}$ defined as more than 95\% DFOB bound is also shown (dotted line). Extraction of the Fe(III)-complex FOB $(108.9 \pm 1.2 \mu \mathrm{M})$ from saline aqueous matrix with $10 \mathrm{mg} \mathrm{TiO} 2 \mathrm{NPs}$ is shown as a control (green square).

Gu et al. calculated a DFOB binding capacity of $8 \mu \mathrm{mol}$ $\mathrm{mL}^{-1}$ for the $\mathrm{Yb}(\mathrm{III})$-COM-IMAC ${ }^{14}$ and of $3.5 \mu \mathrm{mol} \mathrm{mL} \mathrm{m}^{-1}$ for $\mathrm{Ni}\left(\mathrm{II}\right.$ )-IDA-IMAC ${ }^{13,14}$ (or $20 \%$ of all possible binding calculated as per manufacturer information), respectively (Table S8 $\dagger$ ). Therefore, $1 \mathrm{mg}$ of $\mathrm{TiO}_{2}$ NPs bound more DFOB than $1 \mathrm{~mL}$ of the IMAC resins under ideal conditions. The Fe complex corresponding to DFOB, ferrioxamine B (FOB), showed no adsorption onto $\mathrm{TiO}_{2}$ NPs (Fig. 3, green square). This confirmed that only free ligands adsorbed on $\mathrm{TiO}_{2}$ similar to the IMAC methods, suggesting that complexed ligands require a decomplexation step prior to the SPE.

The adsorption of DFOB from ultrapure water onto $\mathrm{TiO}_{2}$ was the same as for saline aqueous matrix. Therefore, we chose the saline aqueous matrix as matrix for all further extrac- 
tion experiments to ensure that singly- and doubly-charged ions did not impede adsorption.

\section{Elution buffer optimization}

Elution of analytes bound on $\mathrm{TiO}_{2}$ is typically achieved by $\mathrm{pH}$ adjustments of the elution buffers. Phosphopeptides/-lipids and glycopeptides, for example, require alkaline conditions to elute from $\mathrm{TiO}_{2} \cdot{ }^{18,32}$ Flavonoids and other catecholate-containing molecules, on the other hand, require apolar solvents and acidic conditions for elution (5\% FA in $50 \% \mathrm{MeOH}^{33}$ or ethanolic citric acid $\left.{ }^{34}\right)$. Some compounds, however, do not elute by adjustment of $\mathrm{pH}$ alone.

Cis-diol-containing molecules, for example, still have a high affinity to $\mathrm{TiO}_{2}$ even under a wide range of $\mathrm{pH}$ and salt concentration. $^{35,36}$

To optimize desorption of hydroxamate type siderophores from $\mathrm{TiO}_{2}$, we tested seven different eluents (each in triplicate). The adsorption efficiency for DFOB was above 99\% among for all replicates prior to the elution $(n=21, \mathrm{RSD}=0.71 \%)$ (Table S1†). E1 (MeOH 100\%) showed low desorption of DFOB (1.4 $\pm 0.1 \%$, Fig. 4), confirming hydroxamic acid ligands do not adsorb on $\mathrm{TiO}_{2}$ because of unspecific hydrophobic interactions. ${ }^{21} \mathrm{E} 2\left(\mathrm{FeCl}_{3} 200 \mu \mathrm{M}, \mathrm{pH} 3.3\right)$ also resulted in low recoveries $(1.6 \pm 0.2 \%)$, indicating that while the complexed FOB did not adsorb, DFOB did not form the complex with Fe(III) after adsorption on $\mathrm{TiO}_{2}$. This result was consistent with previous studies that showed that DFOB forms more stable complexes with $\mathrm{Ti}(\mathrm{IV})$ even in presence of an excess of $\mathrm{Fe}(\mathrm{III}) .{ }^{37,38}$ Surprisingly, E3 $\left(\mathrm{NH}_{3} 10 \%\right.$, $\mathrm{pH}$ 12.6) still showed poor recovery of DFOB $(18.7 \pm 5.2 \%)$. Therefore, pH-adjustment alone did not suffice to desorb hydroxamate-containing ligands from $\mathrm{TiO}_{2}$. In contrast, the $\mathrm{pH}$ of the ammonia E3 solution was sufficient for quantitative desorption of phosphate-containing analytes such as flavin mononucleotide, thiamine monophosphate or pyrophosphate (approximately 90\% recovery). ${ }^{20} \mathrm{E} 4$ $\left(\mathrm{NaH}_{2} \mathrm{PO}_{4} 100 \mathrm{mM}, \mathrm{pH} 8\right)$ also did not elute high proportions of DFOB $(16.9 \pm 0.4 \%)$, despite the well documented ability of inorganic phosphate to compete for $\mathrm{TiO}_{2}$ binding sites. ${ }^{20,39,40}$ The same was observed for E5 $(3.5 \pm 0.4 \%)$, that contained 25 times less phosphate at a higher $\mathrm{pH}$. Only the combination of

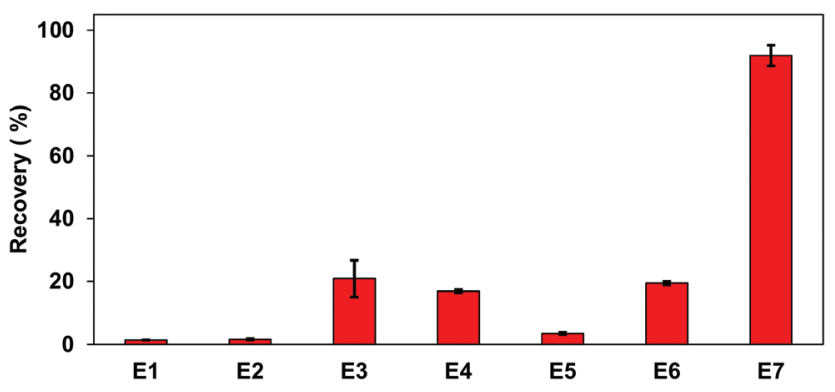

Fig. 4 Comparison of DFOB recoveries using different eluents: $1 \mathrm{~mL}$ of

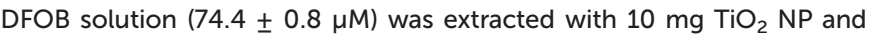
eluted with: $\mathrm{MeOH} 100 \%$ (E1), $\mathrm{FeCl}_{3} 200 \mu \mathrm{M}, \mathrm{pH} 3.3$ (E2), $\mathrm{NH}_{3} 10 \%, \mathrm{pH}$ 12.6 (E3), $\mathrm{NaH}_{2} \mathrm{PO}_{4} 2.5 \mathrm{M}, \mathrm{pH} 8$ (E4), $\mathrm{NaH}_{2} \mathrm{PO}_{4} 100 \mathrm{mM}, \mathrm{pH} 8$ (E5), $\mathrm{NaH}_{2} \mathrm{PO}_{4} 100 \mathrm{mM}, \mathrm{pH} 11$ (E6) and $\mathrm{NaH}_{2} \mathrm{PO}_{4} 100 \mathrm{mM}$ or pH 12.6 (E7). high $\mathrm{pH}$ and a high concentration of phosphate resulted in quantitative DFOB recoveries $(91.9 \pm 3.3 \%)$ from $\mathrm{TiO}_{2}$ (E7, $\mathrm{NaH}_{2} \mathrm{PO}_{4} 100 \mathrm{mM}, \mathrm{pH}$ 12.6). As indicated by low recoveries for E6 $\left(16.8 \pm 0.4 \%, \mathrm{NaH}_{2} \mathrm{PO}_{4} 100 \mathrm{mM}, \mathrm{pH} 11\right)$, elution only occurred at highly alkaline conditions. This apparent connection between phosphate concentration, alkaline $\mathrm{pH}$ and recovery was seemingly in contradiction with the literature, showing no adsorption of phosphate on $\mathrm{TiO}_{2}$ at $\mathrm{pH} \geq 11$. $^{40}$ Our results suggest that phosphate can destabilize the inner-sphere bidentate interaction ${ }^{21}$ between hydroxamate groups and the $\mathrm{TiO}_{2}$ surface at alkaline conditions. However, the exact mechanism of this destabilization is unclear and requires further investigation.

\section{Siderophore concentration from complex matrices}

To test the $\mathrm{TiO}_{2}$ NP SPE method to enrich siderophores from complex biological samples, a siderophore-containing bacterial culture supernatant was spiked with DFOB and then extracted as above. The same supernatant was concentrated by traditional reversed-phased chromatography for comparison. The total DFOB recovery ( $86.5 \mu \mathrm{M}$ initial concentration) was $77.6 \pm 6.2 \%$ with the $\mathrm{TiO}_{2}$ NP SPE compared to less than $0.1 \%$ with $\mathrm{C}_{18}$-SPE (Table 1). The low recovery of DFOB by $\mathrm{C}_{18}$-SPE is consistent with literature values for recoveries from $\mathrm{pH}$ neutral aqueous media. ${ }^{41}$ Results showed that a far greater proportion of siderophores were directly extracted from the same volume of the bacterial culture supernatant with $\mathrm{TiO}_{2}$ NP-based SPE than with the $\mathrm{C}_{18}$-SPE.

For comparison, Braich et al. ${ }^{13}$ showed that approximately $230 \mathrm{nmol}(65 \%)$ of CAS active species (mainly DFOB) were recovered from a $\mathrm{pH}$ adjusted bacterial culture supernatant (Streptomyces pilosus) with a $5 \mathrm{~mL} \mathrm{Ni(II)-IDA-IMAC} \mathrm{column.}{ }^{13}$

The extraction of siderophores with $\mathrm{TiO}_{2} \mathrm{NP}$ was highly specific, indicated by a reduced complexity of the LC-MS base peak chromatogram (Fig. 5B) in comparison to that of the original supernatant (Fig. 5A) and non-specific $\mathrm{C}_{18}$ extract (Fig. 5C). The overlay of the base peak chromatograms with the extracted ion chromatograms of the Fe complex FOB ([M + $\mathrm{H}]^{+}=\left[{ }^{56} \mathrm{Fe}\left(\text { III) } \mathrm{C}_{25} \mathrm{H}_{46} \mathrm{~N}_{6} \mathrm{O}_{8}\right]^{+}, m / z\right.$ 614.2724) and the corresponding Al complex AlOB $\left([\mathrm{M}+\mathrm{H}]^{+}=\left[{ }^{27} \mathrm{Al}(\mathrm{III}) \mathrm{C}_{25} \mathrm{H}_{46} \mathrm{~N}_{6} \mathrm{O}_{8}\right]^{+}\right.$, $\mathrm{m} / z$ 585.3190), showed a clear double-peak in the base peak chromatogram of the $\mathrm{TiO}_{2}$ E7 eluate at 2.37 min (Fig. 5D) but no peaks in the base peak chromatogram of the $\mathrm{C}_{18} \mathrm{MeOH}$ eluate (Fig. 5E).

Table 1 Siderophore recovered amounts and recovery percentages extracted with $\mathrm{C}_{18}$ or $\mathrm{TiO}_{2} \mathrm{NP}$ from a complex bacterial culture supernatant

\begin{tabular}{llll}
\hline & Name & $\mathrm{C}_{18}$ & $\mathrm{TiO}_{2} \mathrm{NP}$ \\
\hline Recovered amount $(\mu \mathrm{mol})$ & DFOB & $0.04 \pm 0.01$ & $67.1 \pm 5.4$ \\
& DFOG1 & $1.0 \pm 0.4^{a}$ & $2.3 \pm 1.5^{a}$ \\
Recovery $(\%)$ & DFOB & $0.03 \pm 0.02$ & $77.6 \pm 6.2$ \\
& DFOG1 & $9.9 \pm 3.4$ & $22.2 \pm 14.6$
\end{tabular}

${ }^{a}$ Approximated with FOB calibration. 

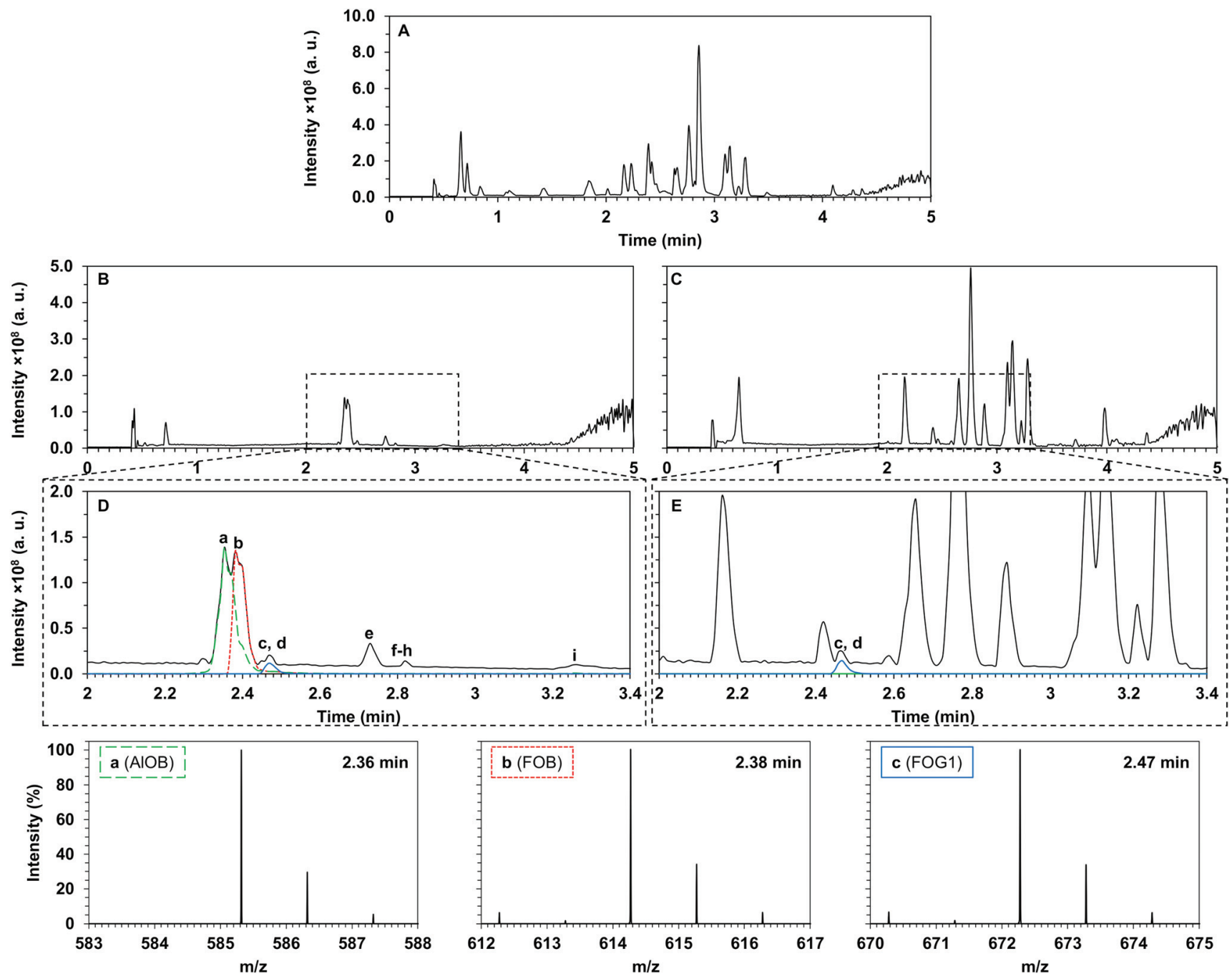

Fig. 5 Comparison of UPLC-HRMS chromatograms: (A) base peak chromatogram (solid black line) of crude bacterial culture spiked with DFOB; (B) base peak chromatogram of the first $\mathrm{TiO}_{2} \mathrm{E7}$ eluate $\left(\mathrm{NaH}_{2} \mathrm{PO}_{4} 100 \mathrm{mM}, \mathrm{pH}\right.$ 12.6); (C) base peak chromatogram of $\mathrm{C}_{18} \mathrm{MeOH}$ eluate; (D) enlarged area of (B) with extracted ion chromatogram of $m / z 614.2724$ analogous $\mathrm{FOB}\left({ }^{56} \mathrm{Fe}(\mathrm{III}) \mathrm{C}_{25} \mathrm{H}_{46} \mathrm{~N}_{6} \mathrm{O}_{8}\right]^{+}$) (red dotted line), $m / z 585.3190$ analogous to AlOB ([ $\left.{ }^{27} \mathrm{Al}(\mathrm{III}) \mathrm{C}_{25} \mathrm{H}_{46} \mathrm{~N}_{6} \mathrm{O}_{8}\right]^{+}$) (green dashed line) and 672.2778 analogous to FOG1 ([ $\left.{ }^{56} \mathrm{Fe}(\mathrm{III}) \mathrm{C}_{27} \mathrm{H}_{48} \mathrm{~N}_{6} \mathrm{O}_{10}\right]^{+}$) (blue solid line); (E) enlarged area of (C) with the same extracted ion chromatograms. (a-i) Peaks showing a ferrioxamine-type fragmentation pattern: (a) AlOB, (b) FOB, (c) FOG1, (d) AlOG1, (e) 3, (f) Fe(III)-1, (g) Al(III)-1, (h) 2, (i) 1.

The investigated bacterial supernatant was CAS and Atkin's assay positive before spiking with DFOB and therefore contained unknown hydroxamate-type siderophore(s). Therefore, we further investigated the remaining peaks in the base peak chromatogram of the $\mathrm{TiO}_{2}$ E7 eluate (a-i in Fig. 5D). The signal at 2.47 min showed coeluting ions with $\mathrm{m} / \mathrm{z} 672.2778$ and $\mathrm{m} / \mathrm{z}$ 670.2817. This characteristic difference $(\Delta m / z=1.9954)$ and the signal intensity ratio of $100 / 6.35\left({ }^{56} \mathrm{Fe} /{ }^{54} \mathrm{Fe}\right)^{42}$ suggested an Fe-containing complex (Fig. 5 FOG1). Mass fragmentation confirmed this complex as ferrioxamine $\mathrm{G}^{43}$ (FOG1, Fig. S5 and Table S2 $\dagger$ ). The Al complex of G1 (AlOG1: $\left[{ }^{27} \mathrm{Al}(\mathrm{III})\right.$ $\left.\mathrm{C}_{27} \mathrm{H}_{48} \mathrm{~N}_{6} \mathrm{O}_{10}\right]^{+}$, with $m / z$ 643.3244) was also detected, but in low intensity.

Assuming similar ionization of FOG1 and $\mathrm{FOB}, \mathrm{C}_{18}$-SPE extracted $9.9 \pm 3.4 \%$ of DFOG1 (approximately $1.0 \pm 0.4 \mu \mathrm{mol}$ ) whereas $2.3 \pm 1.5 \mu \mathrm{mol}$ were extracted with the $\mathrm{TiO}_{2} \mathrm{NP}$ method (22.2 $\pm 14.6 \%$ (Table 1$)$ ). The low recovery of DFOG1 may be due to a large proportion of DFOG1 that was complexed before extraction with $\mathrm{TiO}_{2}$.

The peak at $2.82 \mathrm{~min}$ showed an ion at $(\mathrm{m} / \mathrm{z} 638.2722$ with the ${ }^{54} \mathrm{Fe}$ ion $(\mathrm{m} / \mathrm{z} 636.2763)$ and the $\mathrm{Al}$ complex also detected $(\mathrm{m} / \mathrm{z}$ 609.3190) (Fig. S7†). The metal-free ligand was detected at $3.26 \mathrm{~min}(\mathrm{~m} / \mathrm{z} 585.3610)$. The fragmentation (e.g. neutral loss of $\mathrm{C}_{9} \mathrm{H}_{16} \mathrm{O}_{3} \mathrm{~N}_{2}, 200$ Da Fig. S9 and Table $\mathrm{S} 4 \dagger$ ) indicated an unknown desferrioxamine $\mathbf{1}\left(\mathrm{C}_{27} \mathrm{H}_{49} \mathrm{O}_{8} \mathrm{~N}_{6}\right)$ analogous to the cyclic desferrioxamine $\mathrm{E}$ (Table $\mathrm{S} 5 \dagger$ ). ${ }^{44,45}$ The peak at $2.82 \mathrm{~min}$ $(\mathrm{m} / \mathrm{z}$ 603.3714) suggested a compound with the sum formula of $\mathrm{C}_{27} \mathrm{H}_{51} \mathrm{O}_{9} \mathrm{~N}_{6}$ (2, Fig. S8 $\dagger$ ). $\mathrm{MS}^{2}$ fragmentation experiments (e.g. neutral losses of $\mathrm{C}_{5} \mathrm{H}_{4} \mathrm{O}_{3}(100 \mathrm{Da})$ and $\mathrm{C}_{5} \mathrm{H}_{14} \mathrm{~N}_{2} \mathrm{O}(118 \mathrm{Da})$ (Fig. S10 and Table S6 $\dagger$ )) suggested a un-complexed novel 
Table 2 Summary of parent masses

\begin{tabular}{|c|c|c|c|c|}
\hline Name & $\begin{array}{l}\text { Exp. } m / z \\
{[\mathrm{M}+\mathrm{H}]^{+}}\end{array}$ & $\begin{array}{l}\text { Theo. } m / z \\
{[\mathrm{M}+\mathrm{H}]^{+}}\end{array}$ & $\Delta_{\mathrm{ppm}}$ & $\begin{array}{l}\text { Sum formula } \\
{[\mathrm{M}+\mathrm{H}]^{+}}\end{array}$ \\
\hline DFOB & 561.36078 & 561.36064 & 0.25 & $\mathrm{C}_{25} \mathrm{H}_{49} \mathrm{~N}_{6} \mathrm{O}_{8}$ \\
\hline FOB & 614.27240 & 614.27211 & 0.48 & $\mathrm{C}_{25} \mathrm{H}_{46} \mathrm{~N}_{6} \mathrm{O}_{8} \mathrm{Fe}$ \\
\hline $\mathrm{AlOB}$ & 585.31897 & 585.31870 & 0.46 & $\mathrm{C}_{25} \mathrm{H}_{46} \mathrm{~N}_{6} \mathrm{O}_{8} \mathrm{Al}$ \\
\hline DFOG1 & 619.36702 & 619.36612 & 0.34 & $\mathrm{C}_{27} \mathrm{H}_{51} \mathrm{~N}_{6} \mathrm{O}_{10}$ \\
\hline FOG1 & 672.27783 & 672.27759 & 0.36 & $\mathrm{C}_{27} \mathrm{H}_{48} \mathrm{~N}_{6} \mathrm{O}_{10} \mathrm{Fe}$ \\
\hline AlOG1 & 643.32440 & 643.32418 & 0.34 & $\mathrm{C}_{27} \mathrm{H}_{48} \mathrm{~N}_{6} \mathrm{O}_{10} \mathrm{Al}$ \\
\hline $\mathbf{1}$ (un-complexed) & 585.36096 & 585.36064 & 0.55 & $\mathrm{C}_{27} \mathrm{H}_{49} \mathrm{~N}_{6} \mathrm{O}_{8}$ \\
\hline 1 (Fe(III)-complex) & 638.27222 & 638.27211 & 0.17 & $\mathrm{C}_{27} \mathrm{H}_{46} \mathrm{~N}_{6} \mathrm{O}_{8} \mathrm{Fe}$ \\
\hline 1 (Al(III)-complex) & 609.31903 & 609.31870 & 0.23 & $\mathrm{C}_{27} \mathrm{H}_{46} \mathrm{~N}_{6} \mathrm{O}_{8} \mathrm{Al}$ \\
\hline 2 (un-complexed) & 603.37141 & 603.37120 & 0.34 & $\mathrm{C}_{27} \mathrm{H}_{51} \mathrm{~N}_{6} \mathrm{O}_{9}$ \\
\hline 3 (un-complexed) & 587.37659 & 587.37629 & 0.51 & $\mathrm{C}_{27} \mathrm{H}_{51} \mathrm{~N}_{6} \mathrm{O}_{8}$ \\
\hline
\end{tabular}

hydroxamate analogous to DFOG1 (Fig. S6 and Table S3†). ${ }^{45,46}$ $\mathrm{MS}^{2}$ fragmentation experiments of the ion at $2.73 \mathrm{~min}$ (3, $\mathrm{C}_{27} \mathrm{H}_{51} \mathrm{O}_{8} \mathrm{~N}_{6}, m / z 587.3766 \mathrm{NL} 100 \mathrm{Da}, 118 \mathrm{Da}$, Fig. S11 and Table S7 $\dagger$ ) suggested a further novel un-complexed hydroxamate analogous to DFOG1.

Cumulatively, all peaks in the base chromatogram outside the injection peak and the column bleed could be assigned to siderophores or un-complexed hydroxamates (Fig. S8, $\uparrow$ Table 2 and Table S9†). Only 1 (analogous to the cyclic DFOE) showed the corresponding $\mathrm{Fe}(\mathrm{III})$ - and $\mathrm{Al}(\mathrm{III})$-complexed ions $(\mathrm{m} / \mathrm{z}$ 638.2722 and $m / z 609.3190)$ None of the novel linear hydroxamates (2, 3) showed corresponding Fe(III)-complexed ions despite of excess $\mathrm{Fe}$ in the sample. $\mathrm{MS}^{2}$ experiments suggested one $(\mathbf{1}, \mathbf{2})$ or two $(\mathbf{3})$ fewer hydroxamate groups in comparison to DFOE or DFOG1.

Possibly, fewer hydroxamate groups in these compounds reduced complexation in the sample or changed the detection/ ionization of the complexes but this requires further investigation. The results suggest that the $\mathrm{TiO}_{2} \mathrm{NP}$ SPE also concentrated molecules with one hydroxamate functional group. All analytes were also found in the $\mathrm{C}_{18}$ eluate and the untreated bacterial culture supernatant. The chromatograms and mass spectra of these samples were highly complex and contained 100s of ions with intensities higher than those of the siderophores (Fig. 5E). This result highlights the advantageous selectivity of the $\mathrm{TiO}_{2}$ NP SPE for siderophore discovery and analysis.

\section{Binding of decomplexed siderophores}

By exposing FOB $(12.0 \mathrm{nmol})$ to EDTA $\left(2.5 \times 10^{5} \mathrm{nmol}\right)$ at $\mathrm{pH} 8$ for $24 \mathrm{~h}$, it was possible to increase the total recovery of FOB from $0.07 \mathrm{nmol}(0.6 \%$ recovery, Fig. $6 \mathrm{~B})$ to $1.3 \mathrm{nmol}(10.8 \%$ recovery, Fig. 6A). This result proved that EDTA-de-complexed DFOB could at least partially be recovered from a sample containing a surplus of iron. This result was in contrast to the IDA-IMAC methods where EDTA concentrations exceeding $1 \mathrm{mM}$ EDTA should be avoided. Small concentrations of FOB and AlOB detected in the non-EDTA treatment were likely due to incomplete complexation prior to extraction rather than adsorption of $\mathrm{FOB}$ on $\mathrm{TiO}_{2}$. FOB/DFOB recovery may further be improved with a $\mathrm{pH}$ optimization because ferrioxamine decomplexation with EDTA increases to $\approx 100 \%$ at low $\mathrm{pH}^{47}$

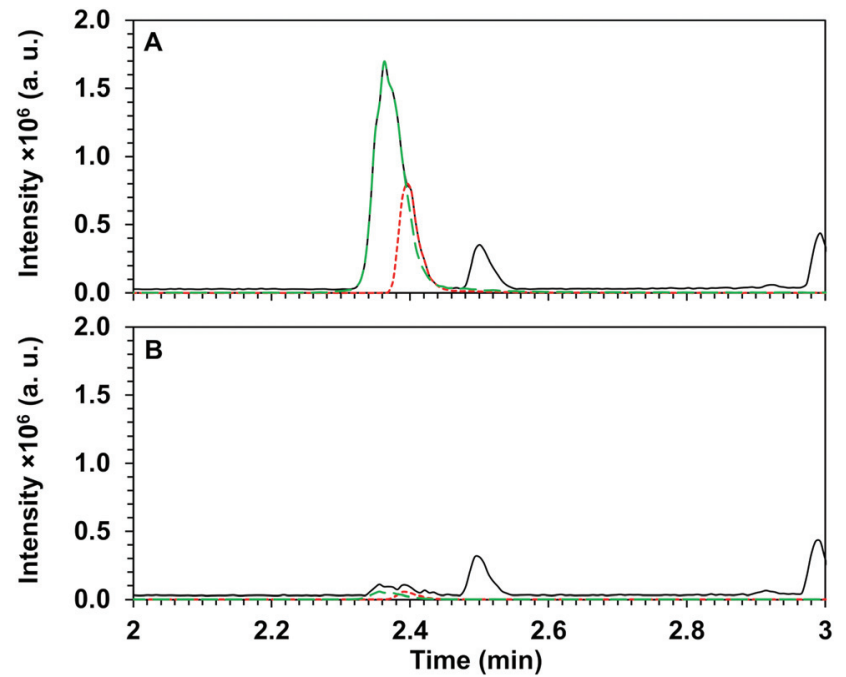

Fig. 6 Comparison of UPLC-HRMS chromatograms (A) with and (B) without EDTA decomplexation step: base peak chromatograms of $\mathrm{TiO}_{2}$ E7 eluate $\left(\mathrm{NaH}_{2} \mathrm{PO}_{4} 100 \mathrm{mM}, \mathrm{pH}\right.$ 12.6) (black solid line) with extracted ion chromatogram of $\mathrm{m} / \mathrm{z} \quad 614.2724$ analogous to $\mathrm{FOB}\left[{ }^{56} \mathrm{Fe}\right.$ (III) $\left.\mathrm{C}_{25} \mathrm{H}_{46} \mathrm{~N}_{6} \mathrm{O}_{8}\right]^{+}$(red dotted line), and $\mathrm{m} / \mathrm{z} 585.3190$ analogous to [ ${ }^{27} \mathrm{Al}(\mathrm{III})$ $\left.\mathrm{C}_{25} \mathrm{H}_{46} \mathrm{~N}_{6} \mathrm{O}_{8}\right]^{+}$(green dashed line).

However, this study aimed at minimal manipulation of the source material and the role of de-complexation ratio or interference of EDTA with siderophore adsorption require further investigation.

\section{Conclusion}

In this study, we developed an efficient and highly specific enrichment of hydroxamate-type siderophores from complex polar protic matrices by $\mathrm{TiO}_{2} \mathrm{NP}$-based SPE. We used the model siderophore DFOB to test the binding capacity of $\mathrm{TiO}_{2}$ NPs for siderophore extraction. The $\mathrm{TiO}_{2}$ NP SPE showed higher binding capacity than the IMAC methods (similar recovery for $1 \mathrm{mg}$ of $\mathrm{TiO}_{2}$ than for $1 \mathrm{~mL}$ of IMAC). A high recovery $(77.6 \pm 6.2 \%)$ of DFOB extracted from complex bacterial culture supernatants with $\mathrm{TiO}_{2} \mathrm{NP}$ was achieved with alkaline buffers containing phosphate. The $\mathrm{TiO}_{2}$ NP SPE also served well as a simple clean-up procedure to selectively process complex samples containing an unknown mixture of siderophores. The $\mathrm{TiO}_{2}$ NP SPE step removed most contaminants and therefore enabled the detection of siderophores or hydroxamates directly from LC-MS base peak chromatogram. We processed CAS assay and Atkin's assay positive bacterial culture supernatants and then easily identified ferrioxamine G1 and other novel ferrioxamines from the most abundant peaks in the base chromatogram due to the drastically reduced mass signatures of the $\mathrm{TiO}_{2}$ extract in comparison to non-specific $\mathrm{C}_{18}$ extracts. All ferrioxamines were also detected in the untreated bacterial culture supernatant, suggesting that the conditions of the $\mathrm{TiO}_{2}$ NP SPE did not alter the composition in the sample. The $\mathrm{pH}$ required for the elution of strong ligands from $\mathrm{TiO}_{2}$, however, 
may be a caveat for the isolation of siderophores susceptible to $\mathrm{pH}$ degradation. We also offered proof-of-principle that a decomplexation step (e.g. with EDTA) enables the adsorption of previously complexed siderophores in samples with high Fe background. Previous studies showed that phospho- or catechol-groups elute with basic or acidic buffer solutions respectively, ${ }^{33,34,48}$ therefore, a future goal to further improve on this method will be to sequentially elute and separate different siderophore classes from complex extracts. The costand labour-efficient concentration and purification of siderophores highlighted in this study may find wide applications in both medical and environmental research to study the role of these molecules in e.g. iron cycling, bacterial competition, primary production and health.

\section{Conflicts of interest}

There are no conflicts to declare.

\section{Acknowledgements}

We thank Jennifer Bergemann for support with the bacterial cultures.

\section{References}

1 E. Ahmed and S. J. M. Holmström, Microb. Biotechnol., 2014, 7, 196-208.

2 R. C. Hider and X. Kong, Nat. Prod. Rep., 2010, 27, 637.

3 B. J. Gobin and M. A. Horwitz, J. Exp. Med., 1996, 183, 1527-1532.

4 J. B. Neilands, J. Biol. Chem., 1995, 270, 26723-26726.

5 C. Adler, N. S. Corbalán, M. R. Seyedsayamdost, M. F. Pomares, R. E. de Cristóbal, J. Clardy, R. Kolter and P. A. Vincent, PLoS One, 2012, 7, 1-7.

6 A. T. Koppisch, C. C. Browder, A. L. Moe, J. T. Shelley, B. A. Kinkel, L. E. Hersman, S. Iyer and C. E. Ruggiero, BioMetals, 2005, 18, 577-585.

7 R. Z. Sayyed and S. B. Chincholkar, Bioresour. Technol., 2006, 97, 1026-1029.

8 R. M. Boiteau, S. J. Fansler, Y. Farris, J. B. Shaw, D. W. Koppenaal, L. Pasa-Tolic and J. K. Jansson, Metallomics, 2019, 11, 166-175.

9 R. M. Boiteau, J. N. Fitzsimmons, D. J. Repeta and E. A. Boyle, Anal. Chem., 2013, 85, 4357-4362.

10 O. Baars and D. H. Perlman, in Application from Engineering with MATLAB Concepts, 2016, p. 189.

11 O. Baars, F. M. M. Morel and D. H. Perlman, Anal. Chem., 2014, 86, 11298-11305.

12 M. Deicke, J. F. Mohr, J. P. Bellenger and T. Wichard, Analyst, 2014, 139, 6096-6099.

13 N. Braich and R. Codd, Analyst, 2008, 133, 877-880.

14 J. Gu and R. Codd, RSC Adv., 2015, 5, 3443-3453.
15 R. Codd, J. Gu, N. Ejje and T. Lifa, in Inorganic chemical biology: Principles, techniques and applications, John Wiley \& Sons, Ltd, Chichester, 1st edn, 2014, pp. 1-35.

16 N. Ejje, C. Z. Soe, J. Gu and R. Codd, Metallomics, 2013, 5, 1519.

17 U. Diebold, Surf. Sci. Rep., 2003, 48, 53-229.

18 M. W. H. Pinkse, P. M. Uitto, M. J. Hilhorst, B. Ooms and A. J. R. Heck, Anal. Chem., 2004, 76, 3935-3943.

19 M. R. Larsen, T. E. Thingholm, O. N. Jensen, P. Roepstorff and T. J. D. Jørgensen, Mol. Cell. Proteomics, 2005, 4, 873886.

20 S. Dziomba, A. Pawelec, K. Ciura, M. Dolegowska, A. Klimowska, W. Rodzaj, M. Guerrouache, B. Carbonnier and B. Wielgomas, Microchem. J., 2019, 145, 784-790.

21 Y. Jing, P. J. Bremer, I. L. Lamont and A. J. McQuillan, Langmuir, 2006, 22, 10109-10117.

22 H. G. Upritchard, J. Yang, P. J. Bremer, I. L. Lamont and A. J. McQuillan, Langmuir, 2007, 23, 7189-7195.

23 H. G. Upritchard, J. Yang, P. J. Bremer, I. L. Lamont and A. J. McQuillan, Langmuir, 2011, 27, 10587-10596.

24 J. Xu, P. Wu, E. C. Ye, B. F. Yuan and Y. Q. Feng, TrAC, Trends Anal. Chem., 2016, 80, 41-56.

25 W. R. McNamara, R. L. Milot, H. E. Song, R. C. Snoeberger, V. S. Batista, C. A. Schmuttenmaer, G. W. Brudvig and R. H. Crabtree, Energy Environ. Sci., 2010, 3, 917-923.

26 B. J. Brennan, M. J. Llansola Portolés, P. A. Liddell, T. A. Moore, A. L. Moore and D. Gust, Phys. Chem. Chem. Phys., 2013, 15, 16605-16614.

27 H. Gulley-Stahl, P. A. Hogan, W. L. Schmidt, S. J. Wall, A. Buhrlage and H. A. Bullen, Environ. Sci. Technol., 2010, 44, 4116-4121.

28 M. Gledhill, P. McCormack, S. Ussher, E. P. Achterberg, R. F. C. Mantoura and P. J. Worsfold, Mar. Chem., 2004, 88, 75-83.

29 B. Schwyn and J. B. Neilands, Anal. Biochem., 1987, 160, 47-56.

30 C. L. Atkin, J. B. Neilands and H. J. Phaff, J. Bacteriol., 1970, 103, 722-733.

31 J. Krenkova, J. Moravkova, J. Buk and F. Foret, J. Chromatogr. A, 2016, 1427, 8-15.

32 M. R. Larsen, S. S. Jensen, L. A. Jakobsen and N. H. H. Heegaard, Mol. Cell. Proteomics, 2007, 6, 1778-1787.

33 J. Kurepa, R. Nakabayashi, T. Paunesku, M. Suzuki, K. Saito, G. E. Woloschak and J. A. Smalle, Plant J., 2014, 77, 443-453.

34 M. A. Khan, W. T. Wallace, S. Z. Islam, S. Nagpure, J. Strzalka, J. M. Littleton, S. E. Rankin and B. L. Knutson, ACS Appl. Mater. Interfaces, 2017, 9, 32114-32125.

35 S. T. Wang, W. Huang, W. Lu, B. F. Yuan and Y. Q. Feng, Anal. Chem., 2013, 85, 10512-10518.

36 S. T. Wang, W. Huang, Y. F. Deng, Q. Gao, B. F. Yuan and Y. Q. Feng, J. Chromatogr. A, 2014, 1361, 100-107.

37 K. E. Jones, K. L. Batchler, C. Zalouk and A. M. Valentine, Inorg. Chem., 2017, 56, 1264-1272.

38 S. Igarashi, K. Yoshida and T. Yotsuyanagi, Bunseki Kagaku, 1991, 40, 571-573. 
39 A. Leitner, TrAC, Trends Anal. Chem., 2010, 29, 177-185.

40 P. A. Connor and A. J. McQuillan, Langmuir, 1999, 15, 2916-2921.

41 H. Waska, A. Koschinsky, M. J. Ruiz Chancho and T. Dittmar, Mar. Chem., 2015, 173, 78-92.

42 E. De Hoffmann and V. Stroobant, Biol. Mass Spectrom., 1991, 20, 142-152.

43 E. Mawji, M. Gledhill, P. J. Worsfold and E. P. Achterberg, Rapid Commun. Mass Spectrom., 2008, 22, 2195-2202.

44 C. H. R. Senges, A. Al-Dilaimi, D. H. Marchbank, D. Wibberg, A. Winkler, B. Haltli, M. Nowrousian,
J. Kalinowski, R. G. Kerr and J. E. Bandow, Proc. Natl. Acad. Sci. U. S. A., 2018, 115, 2490-2495.

45 G. J. Feistner and L. L. Hsieh, J. Am. Soc. Mass Spectrom., 1995, 6, 836-846.

46 G. J. Feistner, D. C. Stahl and A. H. Gabrik, Org. Mass Spectrom., 1993, 28, 163-175.

47 R. Jain, S. Fan, P. Kaden, S. Tsushima, H. Foerstendorf, R. Barthen, F. Lehmann and K. Pollmann, Water Res., 2019, 158, 203-212.

48 Y. Kyono, N. Sugiyama, K. Imami, M. Tomita and Y. Ishihama, J. Proteome Res., 2008, 7, 4585-4593. 